\title{
SOBMEDIDA - CONTROLE DO PESO DURANTE O TRATAMENTO ONCOLÓGICO: A PSICOLOGIA FACILITANDO A PROMOÇÃO DA SAÚDE E DA INTEGRALIDADE: UM RELATO DE EXPERIÊNCIA
}

Fernanda de Souza Fernandes Psicóloga, Faculdade de Ciências Médicas de Minas Gerais, fe-psic@hotmail.com

\section{RESUMO}

Sabe-se que o câncer é um dos maiores problemas de saúde dos países desenvolvidos e em desenvolvimento. Atualmente, é certamente uma das patologias mais temidas. $\mathrm{O}$ diagnóstico de câncer é vivenciado como um momento de imensa angústia e sofrimento. A partir do momento em que se recebe o diagnóstico, dá-se início a um processo interno de dúvidas e incertezas assustadoras. As emoções, os conflitos e as defesas internas tomam a frente do enfrentamento e, geralmente, orbitam a pessoa acometida, oscilando entre suas possibilidades ou recursos internos de vivenciar as experiências do momento vivido. Este cenário está perpassado por vários fatores que geram desconforto emocional, como a batalha às transformaçóes e o impacto na autoimagem, neste sentido a possibilidade de alteraçóes corporais provocadas pelo ganho ponderal pode ter aparecido antes, durante ou após o desenvolvimento da doença e do tratamento. Durante o tratamento, a diminuição da autoestima é crescente, precisando de constantes adaptaçóes às mudanças globais relacionadas ao corpo, ao psicológico e às rela- 
ções sociais. Neste contexto, tornam-se evidentes sentimentos de impotência e medos que acompanham o paciente nesta caminhada, como o ganho ponderal, quando este se torna aparente e ameaçador, por ser um fator de agravo para a proliferação da doença ou de insucesso do tratamento. De acordo com o Relatório de Saúde do Brasil de 2009, divulgado pelo Ministério da Saúde, 46,6\% dos brasileiros estão acima do peso, e que a obesidade tem forte impacto sobre uma das doenças que já se apresenta como a segunda causa de morte no país e no mundo: o câncer. Em 2010-2011, o Brasil terá quase 1 milhão de novos casos: 978.540 (BRASIL, 2009). Ainda segundo o Instituto Nacional do Câncer, consta nos informes do Documento de Políticas e de Ações para Prevenção do Câncer no Brasil: alimentação, nutrição e atividade física, publicado em fevereiro de 2010, pelo INCA, em parceria com o Fundo Mundial para Pesquisa contra o Câncer (WCRF), que uma fração importante dos casos de câncer poderia ser evitada no Brasil, a partir do controle da obesidade. Segundo o relatório, no Brasil, a obesidade é responsável, entre as mulheres, por 29\% dos casos de câncer no corpo do útero, 26\% dos casos de câncer de esôfago, 16\% dos casos de câncer de rim, $14 \%$ dos casos de câncer de pâncreas, 14\% dos casos de câncer de mama e $1 \%$ dos casos de câncer de colorretal. Já nos homens, a obesidade é responsável por $25 \%$ dos casos de câncer de pâncreas, $20 \%$ dos casos de câncer de esôfago, $10 \%$ dos casos de câncer de rim e $8 \%$ dos casos de câncer de colorretal. Vale considerar que, durante o tratamento oncológico, tem-se observado o aumento de casos de ganho ponderal, em decorrência do decréscimo da atividade física, do aumento da ingestão alimentar e da secreção de substâncias hormonais liberadas pelo tecido adiposo, as quais estáo ligadas ao controle dos mecanismos de fome e saciedade. Vale destacar que o desenvolvimento da obesidade durante o tratamento pode interferir de forma direta e/ou indireta na farmacocinética das drogas empregadas no tratamento (KIRJNER; PINHEIRO, 2007). Portanto, pensando na necessidade de se desenvolver trabalhos na perspectiva da promoção da saúde e da integralidade, que, conforme Carta de Ottawa (OMS, 1986), é definida como o processo de capacitação da comunidade para atuar na melhoria da sua qualidade de vida e saúde, incluindo uma maior participação no controle desse processo, a psicologia, junto com a equipe, deve-se apoiar no olhar da inte- 
gralidade, direcionando os profissionais de saúde a pensar sobre o agir em saúde e, especialmente, a ofertar açóes que promovam saúde, previnam riscos de agravo, propiciem assistência aos danos e reabilitação na dinâmica de saúde e de doença. O principal objetivo deste projeto é desenvolver um grupo de apoio de intervenção multiprofissional para pacientes com excesso de peso, em tratamento oncológico, no setor UNACON, do Hospital São José de Criciúma (SC), a fim de que possam receber o auxílio e as ferramentas necessárias para controlarem seus pesos durante o tratamento contra o câncer. A partir da atuação multiprofissional, focalizando os registros do olhar da psicologia hospitalar clínica, revela-se na observação do movimento deste trabalho a importância da realização de encontros grupais com os pacientes em tratamento oncológico, por meio de um espaço de intervenção onde se possa discutir, informar, refletir, intervir e acompanhar a trajetória e controle ponderal dos pacientes. No desenvolvimento do projeto, os participantes encaminhados e interessados foram triados e catalogados pela nutricionista, nas datas divulgadas previamente, em que assinaram o formulário padrão e o Termo de Consentimento Livre e Esclarecido, após encaminhamento médico. Foram selecionados para a primeira edição do projeto 15 pacientes, sendo que os que excederam o número estabelecido pela equipe ficaram em espera para a próxima edição, que acontecerá no início do ano seguinte. Os seis encontros, com frequência mensal e duração média de 1 hora e 30 minutos cada, ficaram a cargo da equipe multidisciplinar (EMQA), sendo que dois facilitadores ficaram responsáveis pelo encontro grupal, de acordo com cronograma preestabelecido, além de evoluir/registrar uma síntese da atividade no prontuário do paciente. Nos encontros, a presença dos demais profissionais se fez necessária. As atividades foram realizadas por meio de vivências, palestras informativas e reflexivas, caminhadas externas, discussão e troca de experiências e acompanhamento nutricional. Essas atividades envolveram os profissionais da equipe multiprofissional. A psicologia hospitalar clínica, na oncologia, propóe o apoio psicossocial e psicoterapêutico, pois grandes são os impactos do diagnóstico e suas consequências, além disso conduz os envolvidos a buscarem suas melhores estratégias de enfrentamento e qualidade de vida. Neste contexto, uma das atribuições deste profissional como membro de equipe multiprofissional é con- 
tribuir no desenvolvimento de estratégias de atuação multiprofissional, a fim de promover a saúde e a integralidade do cuidado aos pacientes. Portanto, diante da realização das atividades no SobMedida, buscou-se direcionar os trabalhos para esta perspectiva e, com o auxílio dos colegas, promover atividades que oferecessem condiçóes oportunas aos pacientes, com intuito de vivenciar demandas que abrissem espaços para informação, discussão e intervenção acerca dos fatores que envolvem obesidade e seus riscos. Trabalhou-se junto com colegas da equipe multiprofissional, ora como colaboradora das atividades propostas, ora como facilitadora. As atividades eram de abertura e vivência do tema do dia, com dinâmicas, reflexóes e fechamento. Das observaçóes realizadas, a partir dos resultados, considerou-se que, nesses encontros grupais, o contato dos pacientes uns com outros, as trocas de experiência, as vivências e as intervençóes da equipe multiprofissional contribuíram relevantemente para o controle e manutenção de seus pesos, embora se tenha conquistado pequena eliminação ponderal. Entretanto, em se tratando de fatores psicossociais, percebeu-se notoriamente a melhora no humor, consciência e, consequentemente, no controle dos níveis de ansiedade e da compulsão alimentar, além de melhorar a relação com a autoimagem, a relaçáo familiar, o relacionamento social e a busca por autocuidado, o que certamente gera uma melhora na qualidade de vida. A partir da experiência vivenciada no grupo SobMedida, considerou-se fundamental a focalização da tentativa de praticar os conceitos de promoção de saúde e de integralidade, em que o contato dos pacientes uns com outros, as trocas de experiência, as vivências e as intervençôes da equipe multiprofissional contribuíram relevantemente para o alcance dos objetivos da equipe multiprofissional, que envolve o controle e manutenção do peso dos pacientes, embora se tenha conquistado pequena eliminação de ganho ponderal. Entretanto, em se tratando de fatores psicossociais, percebeu-se notoriamente a melhora no humor, consciência e, consequentemente, controle dos níveis de ansiedade e da compulsão alimentar, além de melhorar a relaçáo com a autoimagem, a relação familiar, o relacionamento social e a busca por autocuidado, o que gera melhora na qualidade de vida. Verificou-se que é necessária uma manutenção das atividades que mantêm os participantes em contato com a informação e as orientações necessárias, a fim de que estes possam continuar empoderados da transformação da realidade em que se encontram. 
Palavras-chave: Psicologia Hospitalar; Câncer; Integralidade em Saúde; Políticas de Saúde.

\section{REFERÊNCIAS}

BRASIL. Instituto Nacional do Câncer José Alencar Gomes da Silva - INCA. Políticas e açóes para prevenção do câncer no Brasil: alimentação, nutrição e atividade física. Rio de Janeiro: Ministério da Saúde, 2009.

KIRJNER, A.; PINHEIRO, R. L. Interferência da obesidade no tratamento quimioterápico em mulheres com câncer de mama. Revista Brasileira de Cancerologia, São Paulo, v.53, n.3, p.345-354, 2007.

LOTTI, R. C. B. Impacto do tratamento de câncer de mama na qualidade de vida. Revista Brasileira de Cancerologia, São Paulo, v.54, n.4, p.367-371, 2008.

OMS. Carta de Ottawa. In: . Promoção da saúde e saúde pública. Rio de Janeiro: Fundação Oswaldo Cruz, 1986. 